A Risk-Based Rationale for Two-Way Capital Flows:

Why do Capital Flights and Inward Foreign Direct Investments Co-exist?

\author{
Arnab K. Basu \\ College of William and Mary \\ Nancy H. Chau \\ Cornell University
}

College of William and Mary Department of Economics Working Paper Number 4

September 2004 
COLLEGE OF WILLIAM AND MARY

DEPARTMENT OF ECONOMICS

WORKING PAPER \# 4

September 2004

\title{
A Risk-Based Rationale for Two-Way Capital Flows: Why do Capital Flights and Inward Foreign Direct Investments Co-exist?
}

\begin{abstract}
This paper develops a positive theory of two-way capital flows -- the simultaneous outward flight of capital assets, and the inflow of foreign direct investment that acquires ownership of local production units. The basic model exploits insights from entrepreneurial decision making under uncertainty in a general equilibrium setting, and traces out the relationship between (i) entrepreneurial incentives to exploit higher expected profits from risky production activities at the firm level and (ii) the resulting competitive rewards to capital in general equilibrium. The model shows that contrary to expectation, relatively liquid capital assets tend to flow from capital-poor to capital-rich economies, while foreign direct investment aimed at acquiring ownership of production units follows the reversed pattern. We also examine the optimal investment policies for both host and origin countries, and show the rationale behind the inherent conflict of interests between developing and developed economies in the context of capital market liberalization.
\end{abstract}

JEL Classification: F13, F21

Keywords: Cross-Hauling of Capital, Output Uncertainty.

Arnab K. Basu

Department of Economics

College of William and Mary

P.O. Box 8795

Williamsburg, VA 23187-8795

akbasu@wm.edu
Nancy H. Chau

Department of Applied Economics and Management

Cornell University

Ithaca, NY 14853

hyc3@cornell.edu 


\section{Introduction}

Developing countries experiencing massive flights of domestic capital assets abroad are nevertheless frequently major recipients of foreign direct investment. The two faces of this phenomenon of two-way capital flows involve (i) the flight of relatively liquid capital assets that could have contributed to indigenous economic growth, and (ii) the inflow of foreign direct investment that shifts the benefits of ownership of local production units onto the hands of foreign entrepreneurs. Each of these challenges facing emerging economies have been studied extensively, but separately, in the capital flight and foreign direct investment literature. ${ }^{1}$ As inter-related and simultaneous phenomena, however, the root causes of two-way capital flows, and their implications in terms of the welfare of host and origin countries, have nevertheless received very little theoretical attention.

Yet, there are good reasons to believe that the coexistence of capital flight and foreign direct investment in the reverse direction is not simply a matter of theoretical curiosity. We take thirty seven countries under the two regional groupings of Latin American and the Caribbean ${ }^{2}$, and East Asia and Pacific ${ }^{3}$ from 1989 to 1999 as cases in point. Members of both sets of countries underwent substantial capital market liberalization throughout the 90's, as can be seen from the more than many-fold increase in inward foreign direct investment on a per capita basis (Table 1). The size of foreign direct investment is defined here as net inflows of investment that acquire a lasting management interest in local enterprises (10 percent or more of voting stock $)^{4}$.

\footnotetext{
${ }^{1}$ See, for instance, Bhagwati (1964), Bhagwati, Krueger, and Wibulswasdi (1974), Dornbusch (1990), Batra and Ramachandran (1980), Caves (1980), Jones and Dei (1983).

${ }^{2}$ Estimates are computed based on World Development Indicators (2001). Countries and time period available under the regional grouping of Latin America are: Argentina (1989-99), Barbados (1989-99), Brazil (1989-99), Bolivia (1989-99), Chile (1989-99), Colombia (1989-99), Costa Rica (1989-99), Dominican Republic (1989-96), Ecuador (1989, 92), El Salvador (1989-99), Grenada (1989-96), Guatemala (1989-94), Haiti (1989-91), Honduras (1989-99), Jamaica (1989-99), Mexico (1989-93), Paraguay (198999), Panama (1998-99), Peru (1995-98), St. Lucia (1989-96), St. Vincent and the Grenadines (1989-96), Trinidad and Tobago (1989-94), Uruguay (1989-98), Venezuela, RB (1989-99).

${ }^{3}$ Countries and time period available under the regional grouping of East Asia and Pacific are: China (1989-99), Fiji (1989-99), Indonesia (1989-99), Lao PDR (1990-99), Malaysia (1989-99), Mongolia (1993-99), Papua New Guinea (1989-99), Philippines (1989-99), Solomon Islands (1989-99), Thailand (1989-99), Tonga (1989-93), Vanuatu (1989-95), Vietnam (1993-98).

${ }^{4}$ More specifically, it is the sum of equity capital, reinvestment of earnings, other long-term capital, and short-term capital as shown in the balance of payments (World Bank 2001).
} 
We compute the magnitude of capital flights from these countries during the same time period. These estimates employ the residual method, where capital flight is computed as the residual difference between capital inflows and recorded foreign-exchange outflows. Capital inflow is the sum of the change in total external debt outstanding and net foreign direct investment. Foreign-exchange outflows are given by the current account deficit and net additions to reserves and related items (Claessens and Naude 1993). Figure 1 plots all instances of positive capital flight against contemporaneous foreign direct investment inflow of the corresponding country respectively in the two regions. ${ }^{5}$ Evidently, an overwhelming majority (94\%) of all instances of positive capital flights from the thirty seven countries during 1989-1999 are accompanied by strictly positive levels of inward foreign direct investment. ${ }^{6}$

Table 1 and Figure 2 depict the annual regional averages of per capita total capital flight and per capita inward foreign direct investments during 1989-1999 (Figure 2). ${ }^{7}$ As shown, intertemporal increases in inward foreign direct investment exist alongside corresponding increases in capital flight originating from the two regions. Indeed, members of Latin American countries have, on average, higher levels both of per capita capital flight and inward forward direct investment relative to members of East Asian countries.

\footnotetext{
${ }^{5}$ The computed Pearson correlation coefficients based on all available computed values of capital flights are 0.2842 and 0.2353 respectively for East Asia and Latin American. The hypotheses that the two variables cannot be rejected at 1 percent significance level.

${ }^{6}$ It bears emphasis that capital flights are often compounded by foreign exchange outflows such as cross-border bank deposits, or the falsification of trade documents (Dornbush (1990), Bhagwati (1964), Bhagwati et. al (1974)). Pastor (1989) estimates capital flight from Latin American countries based on abnormal or illegal capital outflows as in Dooley (1986). Using these estimates (1982 - 1987), along with reported volumes of inward foreign direct investment in World Bank (2001), Mexico and Brazil respectively rank first and second in terms of the average annual volume of capital flight. Interestingly, Brazil and Mexico are also the top two recipients of inward foreign direct investment during same time period.

${ }^{7}$ These regional averages are computed as total capital flight from a region divided by total population. Only countries with data that span the full sample period 1989 - 1999 are included in the computation (footnote 1).
} 
Table 1

Per Capita Capital Flight and Per Capita Inward FDI (1989-1999)

(East Asia and Pacific (EAP) and Latin America and Caribbean (LAC))

(current US\$)

\begin{tabular}{|l|ll|ll|}
\hline Year & EAP & & LAC & \\
\hline & Capital Flight & FDI & Capital Flight & FDI \\
\hline 1989 & 0.410 & 5.219 & 7.880 & 13.698 \\
1990 & 10.404 & 6.305 & 18.907 & 13.955 \\
1991 & 8.501 & 7.778 & 14.819 & 21.161 \\
1992 & 34.842 & 11.044 & -7.487 & 26.489 \\
1993 & 14.875 & 21.369 & -40.290 & 14.775 \\
1994 & 30.468 & 26.037 & 28.274 & 29.698 \\
1995 & 36.722 & 28.715 & 20.173 & 41.541 \\
1996 & 8.729 & 32.852 & 47.365 & 86.213 \\
1997 & 65.005 & 35.099 & 99.517 & 126.799 \\
1998 & 67.827 & 32.589 & 203.810 & 145.634 \\
1999 & 40.659 & 26.133 & 138.358 & 203.207 \\
\hline Average & 28.949 & 21.195 & 48.302 & 65.743 \\
\hline
\end{tabular}

These observations beg an important question, namely, why do countries that suffer from massive capital flight nevertheless appeal to foreign investors in search of alternative production locations? The objective of this paper is accordingly to examine a theoretical framework based on which a rationale behind these observations can be understood. In the context of the model, the welfare implications of cross-hauling of capital host and origin countries, along with the scope for capital market and investment policies will also be examined.

Specifically, we consider a simple two country (North and South) model of two-way capital flows. The key insights of the basic framework are two-fold, having to do with (i) entrepreneurial incentives and production decision making in the presence of uncertainty and incomplete risk markets at the firm level and (ii) the associated competitively determined returns to capital in general equilibrium. Specifically, production decision making in the presence of uncertainty gives rise to a risk-bearing fee, which shows up in the form of a strictly positive price-cost margin. Thus, if entrepreneurial preferences are of the decreasing absolute risk aversion variety, the risk-induced price-unit cost margin that 
prevails in a capital-poor economy is strictly higher than an otherwise identical capitalrich economy. Perhaps more importantly, the desired price-unit cost margin effectively acts as a tax on the production of the risky output, and puts downward pressure on the derived demand for productive inputs, including capital. This implies, therefore, that all else equal, capital outflows originate from capital-poor economies as a result of the lower returns to capital there. Due to precisely the same set of circumstances - risky production and incomplete risk markets - entrepreneurs in the capital-rich North have an incentive to locate production units in the South, in order to exploit the additional profits that can be extracted in the presence of a strictly larger price-unit cost margin.

In this context of risk-induced cross-hauling of capital, a second objective of this paper is to examine the optimal capital import and export policies of the emerging South, along with those of the North. In particular, we discover an inherent conflict of interest between the two countries, in the sense that unilateral policy making on the part of the South implies a pair of optimal investment taxes, which deter the flow of capital from both directions. Capital exports from the South are to be deterred to safeguard the incentives of Northern entrepreneurs to locate production activities in the South. However, free inflow of Northern investors is not ideal either as it forgoes the possibility of using taxes to extract the rents that Northern entrepreneurs earn in the South.

Meanwhile, standard monopsonistic buyer arguments call for a Northern tax on the inflow of capital from the South. The correct policy towards Northern entrepreneurs who face risky profit prospects operating in the South, however, is a subsidy rather than a tax. These results have clear implications regarding the potential difficulties in formulating international investment rules in the context of the World Trade Organization, or regional agreements such as NAFTA / FTAA, particularly when the two sides of the negotiating table consist respectively of capital-rich and capital-poor countries.

Finally, the basic framework of this paper has its origins in the literature on international trade under uncertainty, wherein the main focus has been to ascertain whether or not standard trade theorems continue to apply in a setting with uncertainty (Helpman and Razin (1990), Mayer (1980), Chau (1998)). In addition, the international factor mobility literature has recently begun to study the question of two-way capital flows. How- 
ever, the main focus has been on North-North interactions (Brainard (1997), Markusen (1995)), whereby oligopolistic multinational firms compete in a noncooperative fashion by choice of production locations both at home and abroad. A key difference between this literature, grounded in "new trade theory", and the model presented here is that our interests lie in understanding North-South interaction in the context of production uncertainty. In addition, we are concerned with capital flight from Southern countries in the form of assets flow that could have been channeled towards productive purposes, rather than the strategic production location decisions between oligopolistic firms per se.

The paper is organized as follows. Sections 2 presents the basic framework in the absence of capital market liberalization, and uncovers how expected profits in risky production, along with the competitive returns to capital, are related to the capital endowment of an economy. Section 3 presents the case of two-country world in which capital markets are liberalized, and show that two-way capital flows indeed prevail in general equilibrium. Section 3 is concerned with the welfare calculus and the formulation of optimal investment policies. Section 4 contains a discussion of the basic assumptions, and broader policy implications of this exercise. Section 5 concludes.

\section{The Basic Model with Output Uncertainty}

In order to capture, in simplest possible terms, the rationale behind risk-induced twoway international flow of capital, we consider a two country (South and North) model, in which production in one of the two sectors is subject to uncertainty in both countries. In addition, throughout the analysis, we use the term capital market liberalization as a regime wherein there is (i) free mobility of physical capital (subject to adjustment costs) between the North and the South; and (ii) free entry of entrepreneurs in each of the two countries, so that any entrepreneur, whether Southern or Northern in origin, is free to set up production units in any of the two countries (again, subject to a cost of investing abroad). For the basic model, we take initial endowment of physical capital ( $\mathcal{K}$ and $\left.\mathcal{K}^{*}\right)$ to be the only difference between the two countries in order to highlight the role of wealth and risk-taking behavior, and relegate additional insights that may be gained from other sources of North-South differences to Section 4. 
Let an asterisk denote Northern variables. The production side of the two countries consist of two sectors, respectively producing a manufacturing output $x_{m}\left(x_{m}^{*}\right)$ and an agricultural output $x_{a}\left(x_{a}^{*}\right)$. Without loss of generality, we take the agricultural output as the numeraire. The world relative price of manufacturing output will be denoted as $p$.

\subsection{Production}

The production of manufacturing output in the two countries takes labor and physical capital as inputs, with

$$
X_{m}=z x_{m}=z G\left(L_{m}, K_{m}\right) ; \quad X_{m}^{*}=z^{*} x_{m}^{*}=z^{*} G\left(L_{m}^{*}, K_{m}^{*}\right)
$$

where $L_{m} \quad\left(L_{m}^{*}\right)$ denote total manufacturing labor employed in the two countries and $K_{m}\left(K_{m}^{*}\right)$ represent capital invested in the manufacturing sector. Planned output $x_{m}=$ $G\left(L_{m}, K_{m}\right)$ and $x_{m}^{*}=G\left(L_{m}^{*}, K_{m}^{*}\right)$ exhibit constant returns to scale with diminishing marginal productivity with respect to both inputs. $z$ and $z^{*}$ are independent and identically distributed random technological parameters with unit mean.

The agricultural sector produces a final output, $x_{a}$, using labor as input, with

$$
x_{a}=\alpha L_{a} ; \quad x_{a}^{*}=\alpha^{*} L_{a}^{*}
$$

where $\alpha>0$ denotes both the average and the marginal productivity of laborers in this sector.

Labor is perfectly mobile intersectorally and there is perfect competition in factor and output markets. Let the two economy's endowment of capital and labor be $\mathcal{K}\left(\mathcal{K}^{*}\right)$ and $\mathcal{L}\left(\mathcal{L}^{*}\right)$, and the competitively determined rewards to capital and labor be given by $r\left(r^{*}\right)$ and $w\left(w^{*}\right)$. The unit (planned output) cost functions of the manufacturing and agricultural sectors can accordingly be denoted as $c_{m}=c_{m}(w, r)$ and $c_{a}=c_{a}\left(w_{a}\right)=\frac{w_{a}}{\alpha}$ for the South, and $c_{m}^{*}=c_{m}\left(w^{*}, r^{*}\right)$ and $c_{a}^{*}=c_{a}\left(w_{a}^{*}\right)=\frac{w_{a}^{*}}{\alpha^{*}}$ for the North.

Full employment of both labor and capital is guaranteed if

$$
L_{m}+L_{a}=\mathcal{L} ; \quad K_{m} \leq \mathcal{K}
$$


where a strict equality is guaranteed if capital markets are not liberalized, and total employment of capital is confined to the amount that is available domestically. If, however, the South is a net exporter of capital, we have $K_{m}=\mathcal{K}-K_{f}$, where $K_{f}$ denotes the volume of capital outflow. Similarly, full employment in factor markets is ensured in the North if and only if

$$
L_{m}^{*}+L_{a}^{*}=\mathcal{L}^{*} ; \quad K_{m}^{*}=\mathcal{K}^{*}+K_{f}
$$

where $K_{f}$ is positive if and only if the North is a net importer of capital.

\subsection{Risk Preferences and the Role of Entrepreneurs}

We now turn to examine the entrepreneurial decision-making calculus, and the question of whether a representative entrepreneur should undertake risky production activities. We begin with the case of capital immobility both in terms of capital, and ownership of production units. As such, $K_{f}=0$, and in addition, the ownership of firms located in each of the two countries cannot be placed in the hands of a foreign entrepreneur.

There is a large number $(N)$ of entrepreneurs in each of the two countries. In addition, each entrepreneur is endowed with $k=\mathcal{K} / N$ units of capital in the South, and $k^{*} \equiv \mathcal{K}^{*} / N$ units of capital in the North. Each individual entrepreneur has identical risk preferences. In particular, the preferences of entrepreneurs over the consumption of the two goods $\left(d_{m}, d_{a}\right)$ are given by a homothetic utility function $u\left(d_{m}, d_{a}\right)$. The associated indirect utility function is denoted as $U\left(W_{i} / b(p)\right)$, with $i=m, a, o$. $W_{i}$ denotes the nominal income of an entrepreneur producing commodity when $i=m, a$, and $W_{o}$ denotes the nominal of a pure capital owner who does not undertake production activities in either sector. $b(\cdot)$ is a price index that is homogeneous of degree one in the two output prices, $p$ and 1 (Stiglitz, 1969; Kilhstrom and Mirman, 1981). The indirect utility function $U$ is taken to be positive, strictly increasing and concave for every positive levels of real income $Y_{i} \equiv W_{i} / b(p)$. We shall denote the Arrow-Pratt measure of absolute risk aversion $-U^{\prime \prime}\left(Y_{i}\right) / U^{\prime}\left(Y_{i}\right)$ as $A\left(Y_{i}\right)$ (Arrow 1971, Pratt 1964).

The nominal income of an entrepreneur operating in the Southern manufacturing sector $\left(W_{m}\right)$, is given by

$$
W_{m} \equiv\left(z p-c_{m}\right) x_{m}+r k \text {. }
$$


Entrepreneurial income in the manufacturing sector thus consists of two parts: (i) random profits $\left(\left(z p-c_{m}\right) x_{m}\right)$ and (ii) rewards from capital ownership, $W \equiv r k$. In the absence of capital mobility, the maximum amount that each unit of capital owned by Southern entrepreneurs can earn is given by $r$.

Taking as given the competitive rewards to capital and labor in the South, the expected utility maximization problem of a Southern entrepreneur operating in the manufacturing sector is given by:

$$
\max _{x_{m}} E U\left(\frac{\left(z p-c_{m}\right) x_{m}+W}{b(p)}\right) ; \quad x_{m} \geq 0 .
$$

The necessary and sufficient conditions for expected utility maximization is thus:

$$
\frac{E U^{\prime}\left(Y_{m}\right) z}{E U^{\prime}\left(Y_{m}\right)} p-c_{m} \equiv \frac{1}{\gamma} p-c_{m}=0
$$

where $\gamma=E U^{\prime}\left(Y_{m}\right) / E U^{\prime}\left(Y_{m}\right) z=\left(p / c_{m}\right)$ is the price-unit cost ratio for output, $x_{m}$, to be positive. In addition, since

$$
\frac{E U^{\prime}\left(Y_{m}\right) z}{E U^{\prime}\left(Y_{m}\right)}=1+\frac{\operatorname{Cov}\left(U^{\prime}\left(Y_{m}\right), z\right)}{E U^{\prime}\left(Y_{m}\right)}<1
$$

if and only if $A\left(Y_{m}\right)>0$, it follows that $\gamma>1$. In other words, as long as the representative entrepreneur is strictly risk averse, $p-c_{m}^{*}=p(\gamma-1) / \gamma>0$. The price-unit cost margin can be interpreted as a risk-bearing fee (Sakai (1978), Pomery (1991)), which compensates for the utility costs of operating in a risky environment.

Similarly, expected utility maximization in the Northern manufacturing sector yields:

$$
\left(\frac{E U^{\prime}\left(Y_{m}^{*}\right) z^{*}}{E U^{\prime}\left(Y_{m}^{*}\right)} p-c_{m}^{*}\right) \equiv \frac{1}{\gamma^{*}} p-c_{m}^{*}=0,
$$

where $Y_{m}^{*}=\left(\left(z^{*} p-c_{m}^{*}\right) x_{m}^{*}+r^{*} k^{*}\right) / b(p)$. Again, the price-unit cost margin in the North in the absence of capital mobility is just $p-c_{m}^{*}=p\left(\gamma^{*}-1\right) / \gamma^{*}>0$. Taken together, equations (6) and (8) imply that the price-unit cost (profit) margin of the manufacturing sector in the South is strictly greater than the price-unit cost margin in the North if and only if $\gamma$ is strictly greater than $\gamma^{*}$. 
Turning now to the agricultural sector, an entrepreneur operating in the safe agricultural sector, earns nominal income $W_{a}$, with

$$
W_{a} \equiv\left(1-c_{a}\right) x_{a}+r k
$$

Thus, the optimization problem of an agrarian entrepreneur can be written analogously as,

$$
\max _{x_{a}} U\left(\frac{\left(1-c_{a}\right) x_{a}+r k}{b(p)}\right) ; \quad x_{a} \geq 0 .
$$

Since $c_{a}=w / \alpha$, profit maximization in agricultural implies that the

$$
\alpha-w=0
$$

as such, $\alpha$ also denotes the economy-wide agricultural wage rate in the South. As should be expected, perfect competition and the absence of risky production in agriculture drive profits to zero, with $1-c_{a}=1-\alpha / w=0$.

The expected utility maximization problem of Northern entrepreneurs can be similarly ascertained. With zero profits in agriculture, the nominal income of a Northern agrarian entrepreneur is just $r^{*} k^{*}$. The economy-wide wage income of laborers in the North is similarly determined by $\alpha^{*}$.

\subsection{Rates of Return to Capital and Expected Profits}

In the absence of international capital mobility, or the possibility of foreign ownership of production units, entrepreneurs in the two countries choose between the production of either or none of the commodities. This implies that the allocation of entrepreneurs between the two sectors is determined by the equalization of expected (indirect) utility across three possible income sources: (i) operating in the manufacturing sector; (ii) operating in the agricultural sector; and (iii) operating in neither and deriving income solely from capital ownership. Entrepreneurs in the South are thus indifferent between operating in manufacturing with nominal income $W_{m}$, or in agriculture with nominal income $W_{a}$ if and only if

$$
E U\left(\frac{\left(z p-c_{m}\right) \tilde{x}_{m}+r k}{b(p)}\right)=U\left(\frac{r k}{b(p)}\right)
$$


where $\tilde{x}_{m}$ is the solution to equation (6) above. Since there is zero excess profit in the agricultural sector, $r k$ gives the nominal income of a pure capital owner, as well as that of an agrarian entrepreneur. Likewise, the allocation of entrepreneurs between the two sectors in the North is determined by the following equality:

$$
E U\left(\frac{\left(z^{*} p-c_{m}^{*}\right) \tilde{x}_{m}^{*}+r^{*} k^{*}}{b(p)}\right)=U\left(\frac{r^{*} k^{*}}{b(p)}\right)
$$

which requires that the expected utilities of entrepreneurs deriving income from any of the three income sources in the North are identical.

The price-unit cost relations in the two sectors, equations (6) and (8), together with the free entry condition, equations (11) and (12), can be used jointly to determine the rewards to capital, and the risk premia in the two countries. As a precursor to the question of whether or not two-way risk induced flow of capital is indeed a possibility, we first set out to examine the way in which differences in capital endowment between the two countries impact (i) the rates of return to capital as captured by $r$ and $r^{*}$, along with entrepreneurial profits in the two countries, as captured by the risk premia $\gamma$ and $\gamma^{*}$.

\subsection{Analysis under Capital Immobility}

Routine manipulation of equation (6) and the implicit relationship between $\gamma$ and the ownership of factors in equation (11) yields the following equation which summarizes the relationship between the risk bearing fee, $k$ and $r$ in the South: ${ }^{8}$

$$
\widehat{\gamma}=-\epsilon(\widehat{r}+\widehat{k})
$$

where a circumflex over a variable denotes proportionate change and $\gamma$ measures the size of the risk bearing fee, as $\gamma=p-c_{m}=p(\gamma-1) / \gamma$. $\epsilon$ denotes the marginal risk premium (Chau (1998)), and represents the risk premium impact of an increase in endowed wealth $r k$. In particular, if the indirect utility function exhibits decreasing absolute risk

\footnotetext{
${ }^{8}$ To see this, note from equation (6) that $\widehat{\gamma}=-\widehat{c}_{m}$ at constant world price, $p$. Equation (13) follows from routine differentiation of the free entry condition in equation (11) taking into account the relationship between $\gamma$ and $c_{m}$ implied by equation (6).
} 
aversion then $\epsilon=-\left[U^{\prime}\left(Y_{a}\right)-E U^{\prime}\left(Y_{m}\right)\right] W / E U^{\prime}\left(Y_{m}\right) c_{m} \tilde{x}_{m}$ is strictly positive. ${ }^{9}$ As such, entrepreneurs endowed with a larger amount of capital are less averse to undertaking risky production activities. The interpretation of equation (13) is as follows: at given world price, and given risk preferences that are of the decreasing absolute risk aversion variety, an increase in income derived from capital ownership on the part of the representative entrepreneur lowers the risk bearing fee required to induce an entrepreneur to undertake risky manufacturing production. This increase in income derived from capital ownership can come from either one of two sources: (i) raising the rate of return to capital $(r)$ or (ii) increasing the endowment of capital for the typical entrepreneur $(k)$.

Another relationship that follows from expected utility maximization is that $\gamma$ also determines the price-cost margin per unit output in the manufacturing sector. In particular, from equation (6), we have,

$$
\widehat{p}=\widehat{c_{m}}+\widehat{\gamma}
$$

It follows therefore that at constant world price, and with the aid of equation (13),

$$
0=\theta_{k m} \widehat{r}-\epsilon(\widehat{r}+\widehat{k})
$$

The relationship between the capital endowment of the representative entrepreneur and the returns to capital in the manufacturing sector is thus characterized by:

$$
\widehat{r}=\frac{\epsilon \widehat{k}}{\left(\theta_{k m}-\epsilon\right)}
$$

In other words, as long as $\left(\theta_{K m}-\epsilon\right)>0,{ }^{10}$ an increase in the capital endowment $k$ contributes to increase the rate of return to capital $r$. Thus, owners of capital in capital

\footnotetext{
${ }^{9}$ To see this, let $\bar{U}=U(r k /(p))$, and $\tilde{U}=U\left(Y_{m}\right)$ be the random utility of a manufacturing entrepreneur. It follows that

$$
\begin{aligned}
U^{\prime}\left(Y_{a}\right)-E U^{\prime}\left(Y_{m}\right) & =U^{\prime}\left(U^{-1}(\bar{U})\right)-E U^{\prime}\left(U^{-1}(\tilde{U})\right) \\
& =U^{\prime}\left(U^{-1}(E \tilde{U})\right)-E U^{\prime}\left(U^{-1}(\tilde{U})\right)
\end{aligned}
$$

where the last equality follows from equation (11). $\epsilon$ is thus strictly positive if and only if $U^{\prime}\left(U^{-1}(\bar{U})\right)-$ $E U^{\prime}\left(U^{-1}(\tilde{U})\right)<0$. Or equivalently, if and only if the function $U^{\prime}\left(U^{-1}(U)\right)$ is strictly convex. In can be readily verified, by definition of the absolute risk aversion coefficient, that decreasing absolute risk aversion is necessary and sufficient for $U^{\prime}\left(U^{-1}(U)\right)$ to strictly convex in $U$.

${ }^{10}$ This condition guarantees that the risk-adjusted factor intensity of the manufacturing sector is strictly positive, and represents a special case of the necessary and sufficient condition for Walrasian Stability in Chau (1998).
} 
abundant countries enjoy higher rates of returns to capital. This paradoxical finding has in fact an intuitive explanation. With risk preferences that exhibit decreasing absolute risk aversion, entrepreneurs in capital-poor economies require a higher risk-bearing fee as an incentive to operate in the risky manufacturing sector. This risk-bearing fee, as equation (14) indicates, behave as if it is a tax on production, in the sense that the fraction of total revenue that entrepreneurs are willing to incur as payments to factor inputs becomes smaller. This, in turn, implies that the return to capital is strictly increasing in the wealth / capital endowment of the representative entrepreneur.

Perhaps more interestingly, an immediate implication of equations (13) and (15) above is that at constant world price, we have

$$
\widehat{\gamma}=-\epsilon(\widehat{r}+\widehat{k})=-\frac{\theta_{k m} \epsilon}{\theta_{k m}-\epsilon} \widehat{k}
$$

It follows, therefore, that the equilibrium risk bearing fee required to induce production in the manufacturing sector is strictly higher in capital-poor economies, as $\widehat{\gamma} / \widehat{k}=$ $-\theta_{k m} \epsilon /\left(\theta_{k m}-\epsilon\right)<0$. Clearly, the price-unit cost margin $p-c_{m}$, which is given simply by $p(\gamma-1) / \gamma$, is also strictly decreasing with respect to $k$. In other words, capital-poor economies are also characterized by a higher manufacturing profit margin. Proposition 1 summarizes these observations.

Proposition 1 If $k^{*}>k$ so that the North is relatively capital rich, then all else equal

1. competitive rewards to capital is higher is the North, with $r^{*}>r$, and

2. the price-cost margin for manufacturing production is strictly higher in the South, with $\gamma>\gamma^{*}$.

Proposition 1 thus sets the stage for an examination of the direction of capital flows and the extent of foreign ownership of production units in the two countries. In particular, with respect to international flows of capital, part 1 of the proposition suggests that the direction of capital flow induced by the presence of production uncertainty is from the capital-poor South to the capital-rich North. Meanwhile, with respect to international differences in entrepreneurial profits, and hence the incentives for entrepreneurs in one country to take over the ownership of production units in the other, part 2 of the proposition suggests that foreign direct investment that concerns ownership transfers are likely 
to flow from the capital-rich North to the capital-poor South.

In what follows, we take a closer look at the validity of these possibilities by incorporating two modifications into the basic model, one each for capital mobility and ownership transfers, in the context of capital market liberalization between the North and the South.

\section{Capital Market Liberalization and Risk-based Cross- hauling of Capital}

Consider therefore the decision on the part of capital owners in the two countries, regarding whether, and by how much, they should invest their capital endowment abroad. We assume that investing capital abroad is costly, and denote $c\left(k_{f}\right)$ as the total cost of investing $k_{f} \geq 0$ amount of capital abroad. $c\left(k_{f}\right)$ is assumed to be increasing and strictly convex, with $c(0)=c^{\prime}(0)=0$. In the process, we shall also incorporate two tax policies which are in place to impede (or encourage if negative) international capital flows: (i) $T=t+t^{*}$ denotes the total capital export tax per-unit physical capital flow $K_{f}$ with $t$ and $t^{*}$ respectively denoting the per unit tax levied by the South and the North on Southern capital exports, and (ii) $\Delta=\delta+\delta^{*}$ denotes the total tax on foreign investors who acquire ownership of production activities in the South, with $\delta$ and $\delta^{*}$ respectively denoting the lump sum tax levied by the South and the North on Northern entrepreneurs.

The nominal income of capital owners in the South, upon investing $k_{f}$ units of capital in the North, is accordingly given by:

$$
W \equiv r\left(k-k_{f}\right)+r^{*} k_{f}-c\left(k_{f}\right)-T k_{f}
$$

Thus, Southern owners of capital maximizes total factor rewards by allocating $\tilde{k}_{f}$ amount of capital in the North, where $\tilde{k}_{f}$ implicitly solves: ${ }^{11}$

$$
r^{*}-r-T=c^{\prime}\left(\tilde{k}_{f}\right) .
$$

\footnotetext{
${ }^{11}$ It can be readily shown that the same investment rule as in equation (18) applies to all Southern entrepreneurs, whether or not they are engaged in the production of the manufacturing output, the agricultural output, or neither. To see this, simply note that maximizing $E U\left(\left(\left(z p-c_{m}\right) x_{m}+W\right) / b(p)\right)$ or $U(W / b(p))$ with respect to $k_{f}$ gives exactly the same necessary and sufficient first order condition as in equation (18) above.
} 
Since $c(\cdot)$ is increasing and strictly concave, $\tilde{k}_{f}$ is thus positive as long as $r^{*}>r+T$. Further, $\tilde{k}_{f}$ is increasing in the rate of return differential $r^{*}-r-t$ between the North and the South. ${ }^{12}$

Turning now to the decision to acquire ownership of production units in the South by Northern producers. Let $F$ be the fixed cost of investment for setting up a production unit in the South. In particular, $F$ is an entrepreneur specific cost parameter, with $F \in[0, \infty]$. The distribution of the fixed cost of investment abroad across the $N$ number of Northern entrepreneurs characterized by a cumulative distribution function $\mu(F)$ and an associated density function $\mu^{\prime}(F)$. The size of $F$ captures any differences between the $N$ Northern entrepreneurs in terms of their local knowledge, and their access to foreign direct investment related expertise which dictate whether or not investing abroad would be a profitable enterprise.

The expected utility maximization problem of a Northern entrepreneur thus consists once again of two stages: (i) determine whether or not to carry out manufacturing / agricultural production activities in the South, or in the North and (ii) determine the expected utility maximizing output level if the first stage decision calls for engaging in production activities either in manufacturing or agriculture. More specifically, the nominal income of a Northern entrepreneur operating in the South is given by: ${ }^{13}$

$$
W^{f}(F)=\left(z p-c_{m}\right) x_{m}^{f}+r^{*} k^{*}-F-\Delta
$$

where $x_{m}^{f}$ denote the planned output level of a Northern firm in the South, which takes as input of production Southern labor $L_{m}^{f}$ and capital inputs via the production function $G\left(L_{m}^{f}, K_{m}^{f}\right)$. A Northern entrepreneur thus prefers undertaking production activities in the South if and only if

$$
E U\left(\frac{\left(z p-c_{m}\right) \tilde{x}_{m}^{f}+r^{*} k^{*}-F-\Delta}{b(p)}\right) \geq \max \left\{E U\left(\frac{\left(z^{*} p-c_{m}^{*}\right) \tilde{x}_{m}^{*}+r^{*} k^{*}}{b(p)}\right), U\left(\frac{r^{*} k^{*}}{b(p)}\right)\right\}
$$

where $\tilde{x}_{m}^{f}$ maximizes the expected utility of a Northern firm located in the South, and

\footnotetext{
${ }^{12}$ Clearly, if $\tilde{k}_{f}>0$, reverse flow of Northern capital $k^{*}$ to the South does not exist, as $r-r^{*}$ must be negative.

${ }^{13}$ It is straightforward to verify that since there is zero profits in Southern agriculture, the flow of foreign direct investment, if it exists, will be directed only to the Southern manufacturing sector.
} 
solves:

$$
\frac{1}{\gamma^{f}} p-c_{m}=0
$$

with $\gamma^{f}=\frac{E U^{\prime}\left(Y^{f}(F)\right)}{E U^{\prime}\left(Y^{f}(F)\right)}$, and $Y^{f}(F)$ is just $W^{f}(F) / b(p)$. Note that since $r<r^{*}$ from Proposition 1, the unit cost of production in the South $c_{m}=c_{m}(\alpha, r)$ is strictly less than the unit cost of production in the North $c_{m}^{*}=c_{m}\left(\alpha^{*}, r^{*}\right)=c_{m}\left(\alpha, r^{*}\right)$. Meanwhile, the left-hand side of equation (19) is strictly decreasing in $F$. It follows from standard arguments that so long as the tax imposed on investment in the South $\Delta$ is not so large as to offset completely the excess profits available from undertaking production in the capital poor South, there exists a strictly positive threshold fixed cost level $\bar{F}$ such that all entrepreneurs with $F \leq \bar{F}$ optimally locate their production units in the South, and $\bar{F}$ implicitly solves

$$
E U\left(\frac{\left(z p-c_{m}\right) \tilde{x}_{m}^{f}+r^{*} k^{*}-\bar{F}-\Delta}{b(p)}\right)=\max \left\{E U\left(\frac{\left(z^{*} p-c_{m}^{*}\right) \tilde{x}_{m}^{*}+r^{*} k^{*}}{b(p)}\right), U\left(\frac{r^{*} k^{*}}{b(p)}\right)\right\}
$$

Finally, since Northern entrepreneurs are at liberty to choose between operating in the manufacturing and agricultural sectors in the North, we have

$$
E U\left(\frac{\left(z p-c_{m}\right) \tilde{x}_{m}^{f}+r^{*} k^{*}-\bar{F}-\Delta}{b(p)}\right)=E U\left(\frac{\left(z^{*} p-c_{m}^{*}\right) \tilde{x}_{m}^{*}+r^{*} k^{*}}{b(p)}\right)=U\left(\frac{r^{*} k^{*}}{b(p)}\right) .
$$

These findings can be summarized as follows:

Proposition 2 If $k^{*}>k$ so that the North is relatively capital rich, then all else equal

1. Southern capital owners will optimally allocate strictly positive amount of capital in the North, with $k_{f}>0$ once capital markets are liberalized so long as the tax $T$ is not too large. In addition, no Northern capital owners can benefit from exporting capital assets to the South.

2. Northern entrepreneurs with $F \leq \bar{F}^{*}$ locate their production activities in the South, once capital markets are liberalized so long as the tax $\Delta$ is not too large. In addition, no Southern entrepreneur can benefit from undertaking production activities in the North.

Proposition 2 thus reiterates the observation made in Proposition 1, that (i) capitalpoor economies are prone to the flight of domestic capital to otherwise identical capitalrich economies, while (ii) the higher expected price-unit cost margin in the capital-poor 
countries are captured by entrepreneurs from capital-rich countries. These observations can have important welfare implications in the context of capital market liberalization. But before we turn to the welfare impacts of two-way cross-hauling of capital discussed above, we first take a closer look at the effectiveness of the two policies $T$ and $\Delta$ in countering the incentives for international capital flows. In particular, since rewards from factor ownership in the South is given by $\left(r^{*}-T\right) k_{f}+r\left(k-k_{f}\right)$, the expected utility of a Southern entrepreneur operating in the manufacturing sector is equal to an agrarian entrepreneur if and only if

$$
E U\left(\frac{\left(z p-c_{m}\right) x_{m}+\left(r^{*}-T\right) \tilde{k}_{f}+r\left(k-\tilde{k}_{f}\right)-c\left(\tilde{k}_{f}\right)}{b(p)}\right)=U\left(\frac{\left(r^{*}-T\right) \tilde{k}_{f}+r\left(k-\tilde{k}_{f}\right)-c\left(\tilde{k}_{f}\right)}{b(p)}\right) .
$$

Expected utility maximization in the manufacturing sector yields first order condition

$$
\frac{1}{\gamma} p-c_{m}=0
$$

where $\gamma=E U^{\prime}\left(Y_{m}\right) / E U^{\prime}\left(Y_{m}\right) z$ denotes the price-unit cost ratio in the South in the presence of capital mobility. Totally differentiating equation (20) above and making use of the free entry condition in equation (21), yields

$$
\widehat{\gamma}=-\epsilon\left(\theta_{r} \widehat{r}+\theta_{k} \widehat{k}+\theta_{k_{f}} \widehat{r}^{*}-\theta_{T} \widehat{T}\right)
$$

where $\theta_{r}$ denotes the share $r\left(k-k_{f}\right) /\left(r\left(k-k_{f}\right)+\left(r^{*}-T\right) k_{f}-c\left(k_{f}\right)\right)$, while $\theta_{k}, \theta_{k_{f}}$ and $\theta_{T}$ denote respectively $r k, r^{*} k_{f}$ and $T k_{f}$ as a share of total rewards from capital ownership for a Southern entrepreneur, $\left(r\left(k-k_{f}\right)+\left(r^{*}-T\right) k_{f}-c\left(k_{f}\right)\right)$. Recall from equation (13) that since the marginal risk premium $\epsilon\left(=-\left[U^{\prime}\left(Y_{a}^{*}\right)-E U^{\prime}\left(Y_{a}\right)\right]\left(r\left(k-k_{f}\right)+\left(r^{*}-T\right) k_{f}-\right.\right.$ $\left.\left.c\left(k_{f}\right)\right) / E U^{\prime}\left(Y_{m}\right) c_{m} \tilde{x}_{m}\right)$ is strictly positive with decreasing absolute risk aversion, it can be easily checked that the Southern risk bearing fee decreases whenever the returns to capital in the South, $r$, or whenever returns to investment in the North, $r^{*}$, increases. Meanwhile, a tax on investment abroad has just the opposite effect, and increases the size of the risk bearing fee required to induce entrepreneurs to operate in the manufacturing sector.

Equation (23), along with equation (14) above thus jointly imply that a tax on investment abroad can in fact spillover to affect the returns to capital in the South via 
the risk bearing fee. More specifically, at constant world price

$$
\begin{aligned}
0 & =\widehat{c_{m}}+\widehat{\gamma} \\
\leftrightarrow 0 & =\left(\theta_{k m}-\epsilon \theta_{r}\right) \widehat{r}-\epsilon\left(\theta_{k} \widehat{k}+\theta_{f} \widehat{r}^{*}-\theta_{T} \widehat{T}\right) .
\end{aligned}
$$

Turning now to Northern entrepreneurs, expected utility maximization of Northern entrepreneurs operating in the North implies that

$$
\frac{1}{\gamma^{*}} p-c_{m}^{*}=0
$$

This condition together with free entry in equation (21) yield

$$
0=\left(\theta_{k m}^{*}-\epsilon^{*}\right) \widehat{r}^{*}-\epsilon^{*} \widehat{k}^{*}
$$

where $\left.\epsilon^{*}=-\left[U^{\prime}\left(Y_{a}^{*}\right)-E U^{\prime}\left(Y_{m}^{*}\right)\right]\left(r^{*} k^{*}\right) / E U^{\prime}\left(Y_{m}^{*}\right) c_{m} \tilde{x}_{m}^{*}\right)$, and has the interpretation that Northern returns to capital is increasing in $k^{*}$ as discussed in Proposition 1. Finally, for the marginal Northern entrepreneur who operates in the South, expected utility maximization in equation (20) along with free entry (equation (21)) jointly imply that

$$
0=\theta_{k m} \widehat{r}-\epsilon^{f}\left(\widehat{r}^{*}+\widehat{k}^{*}\right)+\frac{\bar{F}}{c_{m} \tilde{x}_{m}^{f}} \widehat{\bar{F}}+\frac{\Delta}{c_{m} \tilde{x}_{m}^{f}} \widehat{\Delta}
$$

where $\epsilon^{f}$ denotes the marginal risk premium of the intra-marginal Northern entrepreneur operating in the South $\left(\epsilon^{f}=-\left[U^{\prime}\left(Y_{a}^{*}\right)-E U^{\prime}\left(Y^{f}\right)\right] r^{*} k^{*} / E U^{\prime}\left(Y^{f}\right) c_{m} \tilde{x}_{m}^{f}\right)$. In the context of capital market liberation, equations (24) - (26) jointly provide the general equilibrium impacts of the two taxes ( $T$ and $\Delta$ ) on two rates of return to capital $r$ and $r^{*}$, along with the fixed cost of the intra-marginal entrepreneur $\bar{F}$. In particular, from equation (25), it can be readily seen that $r^{*}$ is independent of the two tax rates, and depends instead only on the capital endowment of Northern entrepreneurs, $k^{*}$. However,

$$
\begin{aligned}
\widehat{r} & =-\frac{\epsilon \theta_{T}}{\theta_{k m}-\epsilon \theta_{r}} \widehat{T} \\
\widehat{\bar{F}} & =\frac{c_{m} \tilde{x}_{m}^{f}}{\bar{F}}\left(\frac{\theta_{k m} \epsilon \theta_{T}}{\theta_{k m}-\epsilon \theta_{r}} \widehat{T}-\frac{\Delta}{c_{m} \tilde{x}_{m}^{f}} \widehat{\Delta}\right)
\end{aligned}
$$

Thus, Southern returns to capital is decreasing in $T .{ }^{14}$ The intuition follows straightforwardly from the definition of the Southern risk-bearing fee - by decreasing the income

\footnotetext{
${ }^{14}$ Note that since $\theta_{r}<1$, the denominator of the right hand side expression of equation (27) is strictly positive so long as the risk adjusted factor share $\theta_{k m}-\epsilon$ in equation (16) is strictly positive.
} 
of the Southern entrepreneurs, the risk-bearing fee $\gamma$ rises in the South, and as such, the demand for capital in the South also decreases. This reduction in the returns to capital immediately implies that the cost of production in the South, $c_{m}$, declines even further. As such, a tax on capital movement, $T$, has the added effect of stimulating the movement of Northern entrepreneurs to the South. Put another way, the share of Northern entrepreneurs that operate in the South $\mu(\bar{F})$ is strictly increasing in the tax on Southern capital export $T$.

In terms of the tax on Northern entrepreneurs operating in the South, note that as $\Delta$ raises the cost of locating production in the South, an increase in $\Delta$ decreases the fixed cost of the marginal entrepreneur by exactly the same amount, with $d \bar{F} / d \Delta=-1$. However, raising $\Delta$ only impact the profits of Northern entrepreneurs, and as such it has no bearing on the risk premium of Southern entrepreneurs. It follows that Southern returns to capital $r$ is independent of $\Delta$.

Proposition 3 If $k^{*}>k$, then all else equal

1. an increase in the tax on the flow of capital assets from the South to the North, $T$, lowers Southern returns to capital, and encourages Northern entrepreneurs to undertake manufacturing production activities in the South;

2. an increase in the tax on Northern entrepreneurs who operate in the South, $\Delta$, has no impact on the returns to capital in the South, and deters the outflow of Northern entrepreneurs.

\section{Welfare Considerations in the Presence of Cross- hauling}

An important point of inquiry that remains would seem to be whether or not free inflows and outflows of capital is unconditionally beneficial to the two countries involved. We begin examining this question by evaluating the welfare of the South as the certainty equivalent income of the $N$ entrepreneurs, the wage income of the $\mathcal{L}$ laborers, along with the tax revenue from the two policies $\Delta$ and $T$. 
By definition, free mobility guarantees that the expected utility of entrepreneurs in the manufacturing sector coincides with the (risk-free) utility of agrarian entrepreneurs and pure capital owners. It follows, therefore, that the certainty equivalent income of the $N$ entrepreneurs is simply given by $N\left(\left(r^{*}-T\right) k_{f}+r\left(k-k_{f}\right)-c\left(k_{f}\right)\right)$. In addition, total tax revenue collected via the import and export tax on capital equals $\delta N \mu(\bar{F})+t N k_{f}$. Southern welfare is thus:

$$
\begin{aligned}
V & =N\left(\left(r^{*}-T\right) k_{f}+r\left(k-k_{f}\right)-c\left(k_{f}\right)\right)+w \mathcal{L}+\delta N \mu(\bar{F})+t N k_{f} \\
& =N\left(\left(r^{*}-t^{*}\right) k_{f}+r\left(k-k_{f}\right)-c\left(k_{f}\right)\right)+w \mathcal{L}+\delta N \mu(\bar{F})
\end{aligned}
$$

Recall from Proposition 2 that an increase in the capital export tax, $T=t+t^{*}$, is shown to have a negative impact on the returns to Southern capital, but provide added impetus for foreign entrepreneurs to set up production units in the South. The implication on Southern welfare subsequent to an increase in the capital export tax $t$ can therefore be expected to be two-fold: first, it distorts the capital allocation decisions of Southern entrepreneurs between the North and the South. Second, by artificially lowering the cost of production in the South (as $r$ decreases with $T$ ), the same distortionary tax on capital outflow enables an increase in total tax revenue that the Southern government can extract from foreign entrepreneurs via an increase in $\delta$. We have, therefore,

$$
\begin{aligned}
\frac{\partial V}{\partial t} & =N\left(\left(r^{*}-t^{*}-r-c^{\prime}\left(k_{f}\right)\right) \frac{\partial k_{f}}{\partial t}+\left(k-k_{f}\right) \frac{\partial r}{\partial t}+\delta \mu^{\prime}(\bar{F}) \frac{\partial \bar{F}}{\partial t}\right) \\
& =N\left(t \frac{\partial k_{f}}{\partial t}+\left(k-k_{f}\right) \frac{\partial r}{\partial t}+\delta \mu^{\prime}(\bar{F}) \frac{\partial \bar{F}}{\partial t}\right)
\end{aligned}
$$

where the second equality follows from equation (18). Thus, even though both $k_{f}$ and $r$ decrease with the capital export tax $t$, there remains a positive government revenue rationale for putting checks on capital exports. Specifically, a tax that deters the flight of Southern capital attracts the inflow of Northern entrepreneurs. The subsequent gains in government revenue via the $\operatorname{tax} \delta$ can nevertheless exceed the negative welfare consequence of capital export deterrence. Clearly, this will be the case if the marginal investor deterrence effect as parameterized $\mu^{\prime}(\bar{F})$ - the increment in the number of foreign entrepreneurs as the fixed cost of the intra-marginal entrepreneur increases - is sufficiently large, and if the tax on the inflow of Northern entrepreneurs $\delta$ is positive. 
Indeed, it can be readily shown that the optimal Southern tax on Northern direct investment $\delta$ is strictly positive. To this end, recall from Proposition 2 that an increase in $\delta$ has no impact on the two rates to return to capital $r$, and $r^{*}$ (and hence $k_{f}$ ), and we have

$$
\frac{\partial V}{\partial \delta}=N\left(\delta \mu^{\prime}(\bar{F}) \frac{\partial \bar{F}}{\partial \delta}+\mu(\bar{F})\right)
$$

It follows that the optimal Southern $\operatorname{tax} \tilde{\delta}$ on the inflow of Northern entrepreneurs is strictly positive, with

$$
\tilde{\delta}=\frac{-\mu(\bar{F})}{\mu^{\prime}(\bar{F}) \frac{\partial \bar{F}}{\partial \delta}}
$$

which balances exactly the direct effect of the increase in government revenue per unit increase in $\delta$, and the associated reduction in government revenue as Northern entrepreneurs respond by relocating their production units away from the South.

Proposition 4 In the presence of risk-based cross-hauling of Southern capital and Northern production investments due to unequal capital endowments $\left(k<k^{*}\right)$,

1. the optimal Southern tax on capital flight to the North, $t$, is strictly positive if $\delta$ is positive, and if the foreign entry effect of the capital import tax, $\mu^{\prime}(\bar{F})(\partial \bar{F} / \partial t)$, is sufficiently large,

2. the optimal Southern tax on Northern investment in the South $\delta$ is always strictly positive.

In sum, from the point of view of the capital-poor South, a tax on Northern investment serve to extract at least part of the profits $\left(p-c_{m}\right) \tilde{x}_{m}^{f}=p\left(\gamma^{f}-1\right) \tilde{x}_{m}^{f} / \gamma^{f}$ generated whenever preferences exhibit risk aversion, and $\gamma^{f}>1 .{ }^{15}$ Precisely due to the revenue motive behind foreign investment taxation, the South will benefit even further by deterring the flight of productive capital abroad by lowering the cost of production in the South, so as to counter the investment disincentives generated by the capital import tax.

\footnotetext{
${ }^{15}$ Clearly, if profits are competed to zero, as would be the case either when entrepreneurs are risk neutral, or when manufacturing production is risk-free, any tax on Northern investment in the South will render profits strictly negative, and put a stop to the inflow of Northern investment altogether.
} 
We now turn to Northern welfare $V^{*}$, which consists of the certainty equivalent income of the $N$ entrepreneurs investing in the North and in the South, Northern laborers' income, along with any investment tax revenue:

$$
\begin{aligned}
V^{*}= & N(1-\mu(\bar{F})) r^{*} k^{*}+N \int_{0}^{\bar{F}} b(p) U^{-1}\left[E U\left(\frac{\left.\left(z p-c_{m}\right) \tilde{x}_{m}^{f}+r^{*} k^{*}-F-\Delta\right)}{b(p)}\right)\right] d \mu(F) \\
& +w^{*} \mathcal{L}^{*}+t^{*} N k_{f}+\delta^{*} N \mu(\bar{F}) .
\end{aligned}
$$

Since $\bar{F}$ increases with the capital export tax $t^{*}$, while $r$ and $k_{f}$ are both strictly decreasing in $t^{*}$ from Proposition 3, the effect of a tax on Southern capital export can be expected to be three-fold. First, it directly contributes to Northern tax revenue. Second, it indirectly affects the income of Northern entrepreneurs operating in the South as the returns to capital in the South declines with $t^{*}$. Finally, it indirectly impacts government revenue available from its tax / subsidy on Northern entrepreneurs operating in the South. More specifically,

$$
\begin{aligned}
\frac{\partial V^{*}}{\partial t^{*}}= & {\left[N k_{f}+N t^{*} \frac{\partial k_{f}}{\partial t^{*}}\right]-N \int_{0}^{\bar{F}} \frac{E U^{\prime}\left(Y^{f}(F)\right) K_{m}^{f}}{U^{\prime}\left(Y_{c}^{f}(F)\right)}\left(\frac{\partial r}{\partial t^{*}}\right) d \mu(F) } \\
& +\delta^{*} N \mu^{\prime}(\bar{F}) \frac{\partial \bar{F}}{\partial t^{*}}
\end{aligned}
$$

where $Y_{c}^{f}(F)$ is the certainty equivalent real income of a Northern entrepreneur operating in the South, with $Y_{c}^{f}(F)=U^{-1}\left[E U\left(\frac{\left.\left(z p-c_{m}\right) \tilde{x}_{m}^{*}+r^{*} k^{*}-F-\Delta\right)}{b(p)}\right)\right]$. The first expression in square brackets in equation (34) represents a direct revenue motive for taxing foreign capital inflow, and is strictly positive so long as $t^{*}$, and hence the negative revenue effect due to reverse capital flow $t^{*}\left(\partial k_{f} / \partial t^{*}<0\right)$ is not too large. For the second reason why it is in the interest of the North to limit Southern capital inflow, recall that the price of employing capital input by Northern entrepreneur is strictly decreasing in $t^{*}$, it follows that deterring Southern capital inflow serves an additional profit motive, by raising the profits of Northern entrepreneurs operating in the South even further. The third term in equation (34) concerns Northern government revenue available from taxing entrepreneurs operating abroad. Clearly, as $t^{*}$ in effect encourages Northern entrepreneurs to operate in the South, this government revenue impact can adversely affect Northern welfare, if $\delta^{*}$ is negative and represents a subsidy on Northern entrepreneurs in the South.

To this end, it can be confirmed that the optimal policy on Northern investment 
in the South is indeed a subsidy, since

$$
\frac{\partial V^{*}}{\partial \delta^{*}}=-N \int_{0}^{\bar{F}} \frac{E U^{\prime}\left(Y^{f}(F)\right)}{U^{\prime}\left(Y_{c}^{f}(F)\right)} d \mu(F)+N \mu(\bar{F})+\delta^{*} N \mu^{\prime}(\bar{F}) \frac{\partial \bar{F}}{\partial \delta^{*}}<\delta^{*} N \mu^{\prime}(\bar{F}) \frac{\partial \bar{F}}{\partial \delta^{*}}<0 .
$$

The first inequality follows from decreasing absolute risk aversion since $E U^{\prime}\left(Y^{f}(F)\right)>$ $U^{\prime}\left(Y_{c}^{f}(F)\right){ }^{16}$ Intuitively, whereas government revenue rises with a tax on the outflow of Northern entrepreneurs to the South, the reduction in certainty equivalent income of risk averse entrepreneurs is strictly greater than the gains in government revenue. The second inequality follows whenever $\delta^{*}>0$ from Proposition 3.

The optimal Northern subsidy on Northern investment in the South is thus given by:

$$
-\tilde{\delta}^{*}=-\frac{\int_{0}^{\bar{F}} \frac{E U^{\prime}\left(Y^{f}(F)\right)}{U^{\prime}\left(Y_{c}^{f}(F)\right)} d \mu(F)-\mu(\bar{F})}{\mu^{\prime}(\bar{F}) \frac{\partial \bar{F}}{\partial \delta^{*}}}>0 .
$$

We have, therefore

Proposition 5 In the presence of risk-based cross-hauling of Southern capital and Northern production investments due to unequal capital endowments $\left(k<k^{*}\right)$,

1. the optimal Northern tax on capital import from the South is strictly positive if the direct capital import tax revenue motive $\left[N k_{f}+N t^{*}\left(\partial k_{f} / \partial t^{*}\right)\right]$, along with the entrepreneurial profit motive of the capital import tax, dominate the increase in government subsidy to Northern entrepreneurs in the South, and

2. the optimal Northern subsidy on direct investment flows from the North to the South is strictly positive.

\section{Discussion}

The aim of the basic model is to illustrate, with a minimal set of assumptions, the possibility of risk-based cross-hauling of international capital flows, and the associated welfare consequences. Here, we relax a number of the key assumptions in the analysis so far.

\footnotetext{
${ }^{16}$ See footnote 5 .
} 


\section{Risky production in agriculture}

To begin with, we have assumed that the capital intensive manufacturing sector is the only production activity that is subject to uncertainty. However, it is equally likely that agrarian production is also risky, due to uncertain climatic and other productivity changes that are typical of agricultural production (Newbery and Stiglitz (1981)). It can be readily verified that the basic model can be modified to accommodate these changes. In particular, let $z_{a}$ and $z_{m}$ denote the identical and independently distributed technological parameters of the two sector, both with unit mean. Expected utility maximization by entrepreneurs operating in the two sectors thus imply a system of two risk-adjusted price equals unit cost relations, with

$$
\frac{1}{\gamma_{m}} p=c_{m}(w, r) ; \frac{1}{\gamma_{a}}=c_{a}(w) .
$$

where $\gamma_{m}=E U^{\prime}\left(Y_{m}\right) / E U^{\prime}\left(Y_{m}\right) z_{m}$ and $\gamma_{a}=E U^{\prime}\left(Y_{a}\right) / E U^{\prime}\left(Y_{a}\right) z_{a}$ are both greater than one, and represent respectively the size of the price-unit cost gap in the two sectors required to induce entrepreneurs to undertake risky production activities in these two sectors. In addition, $Y_{a}=\left(\left(z_{a}-c_{a}\right) x_{a}+W\right) / b(p)$ is the random real income of agricultural entrepreneurs. Expected utilities of entrepreneurs in manufacturing and in agriculture, are the same as that of a pure factor owner if and only if

$$
E U\left(\frac{\left(z_{m} p-c_{m}\right) \tilde{x}_{m}+r k}{b(p)}\right)=E U\left(\frac{\left(z_{a}-c_{a}\right) \tilde{x}_{a}+r k}{b(p)}\right)=U\left(\frac{r k}{b(p)}\right)
$$

Expected utility maximization and free mobility of entrepreneurs imply, therefore, that

$$
\begin{aligned}
0 & =\widehat{c_{m}}+\widehat{\gamma}_{m} \\
& =\theta_{l m} \widehat{w}+\theta_{k m} \widehat{r}-\epsilon_{m}(\widehat{r}+\widehat{k}) \\
0 & =\widehat{w}+\widehat{\gamma}_{a} \\
& =\widehat{w}-\epsilon_{a}(\widehat{r}+\widehat{k})
\end{aligned}
$$

where $\epsilon_{i}$ is the marginal risk premium for entrepreneurs operating in sector $i$. Equations (37) - (38) imply:

$$
\frac{\widehat{w}}{\widehat{k}}=\frac{\epsilon_{a} \theta_{k m}}{\theta_{l m} \epsilon_{a}+\theta_{k m}-\epsilon_{m}}>0 \frac{\widehat{r}}{\widehat{k}}=\frac{\epsilon_{m}-\theta_{l m} \epsilon_{a}}{\theta_{l m} \epsilon_{a}+\theta_{k m}-\epsilon_{m}}>0 .
$$


The second inequality holds if the share of labor in the manufacturing sector $\theta_{l m}$ is less than $\epsilon_{m} / \epsilon_{a}$. The intuition is straightforward. As entrepreneurial income rises with $k$, the willingness to undertake risk rises in both the agrarian and the manufacturing sectors. The result is an increase in demand for labor, which in turn bids up the competitive returns to labor $w$. It follows, therefore, that the increase in the willingness to undertake risk in the manufacturing sector strictly dominates the increase in the economy-wide competitive wage $w$ if and only if the share of labor in the manufacturing sector is not too large. This gives the analogue of Part 1 of Proposition 1, wherein capital-poor economies are found to have lower returns to capital.

In addition, equations (37) - (38) also imply:

$$
\frac{\widehat{\gamma}_{m}}{\widehat{k}}=-\frac{\epsilon_{m} \theta_{k m}}{\theta_{l m} \epsilon_{a}+\theta_{k m}-\epsilon_{m}}<0
$$

and hence Part 2 of proposition 1 remains robust even when both the manufacturing and agricultural sectors are subject to uncertainty. In other words, capitalpoor economies are prone to two-way capital flows, as returns to capital rises with $k$, while the profit (price-cost) margin in manufacturing is lower in capital rich economies. ${ }^{17}$

\section{Technological differences}

The analysis above does not preclude a popular reason behind capital flight that Northern technological superiority naturally gives rise to higher demand, and hence higher returns to capital. For instance assume that $k$ and $k^{*}$ are exactly the same, but the Northern unit cost of manufacturing production, $c_{m}(w, r) / a$ (where $a>1$ is a Hicks neutral technological change parameter) is strictly less than that of the South, $c_{m}(w, r)$, at constant $w$ and $r$. Therefore, in the risk-free analogue of our model, wherein technology is the only source of difference between the North and the South, profit maximization in the North implies that $p=c_{m}\left(w^{*}, r^{*}\right) / a$,

\footnotetext{
${ }^{17}$ In this context, the possibility of Northern investment in Southern agriculture also arises, due once again to the higher risk premium associated with agricultural production in the South in general equilibrium. Since $\widehat{\gamma}_{a} / \widehat{k}=-\widehat{w} / \widehat{k}<0$ from equation (39), the price-cost margin in South agriculture is indeed higher in the capital-poor South.
} 
and hence

$$
\widehat{a}=\theta_{k m} \widehat{r}^{*}
$$

Thus, as may be expected, $a>1$ implies that $r^{*}>r$ in the absence of international capital mobility. Capital flight from the South to the North should therefore be an anticipated consequence of capital market liberalization. However, it bears emphasis that technological differences alone cannot justify the two-way crosshauling of foreign direct investment as shown in Proposition 2. In particular, since the price-cost margin $p-c_{m}(w, r)$ in the South, and in the North $p-c_{m}\left(w^{*}, r^{*}\right) / a$ are both driven down to zero in the presence of free entry, it makes little sense for Northern entrepreneurs to incur a fixed cost $F$ to take the production activities away from the North.

\section{Decreasing marginal product in agriculture}

Another simplifying assumption made in the basic model concerns constant returns in agriculture, so that the competitive returns to labor is independent of the endowment of capital in the economy. Suppose in contrast that agriculture exhibits decreasing marginal product, so that in order for agriculture to accommodate an increasing number of workers, the wage rate $w$ must decline. A moment's reflection should reveal that this extension of the basic model is formally equivalent to the standard specific-factors model (Jones (1971)), in which one of the results is that the income of the mobile factor (labor) is increasing in the endowment of either of the two specific factors.

It should therefore be apparent that our predictions in Propositions 1 and 2 remain robust, in the sense that a capital-poor economy appeals to foreign direct investment, but can also be vulnerable to capital flight. In particular, (i) the competitively determined capital rent $r$ is relatively low due to Southern entrepreneurs' aversion to risks, and in addition (ii) the wage rate $w$ is also lower precisely due to the relative lack of demand for labor services in a capital-poor economy. All else equal, these two factors combined implies that the wider price-unit cost margin for entrepreneurs operating in the South is once again the key rationale behind two-way flows of capital. 


\section{Conclusion}

The results in this paper highlight the implications of capital market liberalization and underscores the fact that under production uncertainty and incomplete risk markets, capital flight takes place from countries that are poorly endowed with capital to those that are relatively capital-rich. The basic framework exploits the insights from entrepreneurial decision making under production uncertainty in the manufacturing sector, and the general equilibrium consequence of risky production on the relative rates of returns to capital in capital-poor and capital-rich economies. The model shows that the rationale behind two-way capital flow is surprisingly simple - that the risk-bearing fee attached to risky production shows up in the form of a price-unit cost margin. In the presence of preferences that exhibit decreasing absolute risk aversion, capital-poor entrepreneurs are willing to devote a smaller share of their revenue to pay for productive inputs. The resulting downward pressure on the derived demand for capital inputs implies that other things being equal, the flight of capital originates from capital-poor countries to capitalrich countries. By the same token, the higher price-cost margin in the South induces foreign direct investment flows from the North to the South, as entrepreneurs in capitalrich economies are more likely to undertake risky production activities.

In terms of welfare, the investment policies of the two countries differ considerably. In particular, whereas the revenue motive constitute the rationale behind Southern taxation of both capital inflow as well as capital outflow, the welfare maximization policy of the North actually implies that Northern investment in the South should be encouraged via subsidies, rather than deterred. These findings shed new light on the potential

conflict of interests between capital-rich and capital-poor economies in the context of capital market liberalization. 


\section{References}

Arrow, K. J. 1971. "The Theory of Risk Aversion" in K.J. Arrow, Essays in the Theory of Risk Bearing. Markham, Chicago.

Bhagwati, J. (1964). "On the Under invoicing of Imports," Bulletin of the Oxford University, Institute of Economics and Statistics, vol. 26: 389-397.

Bhagwati, J. , A. Krueger, and C. Wibulswasdi (1974), "Capital Flight from LDCs: A Statistical Analysis," in J. N. Bhagwati, ed., Illegal Transactions in International Trade, Amsterdam, North Holland, 1974.

Brainard, S. L. (1993). "An Empirical Assessment of the Proximity-concentration Tradeoff between Multinational Sales and Trade", American Economic Review 87: 520-544.

Caves, R. E. (1982) Multinational Enterprises and Economic Analysis. Cambridge University Press.

Chau, N. H. (1998). "Dynamic Stability and International Trade Under Uncertainty", Economica 65: 381-399.

Claessens, S., and D. Naude. (1993). "Recent Estimates of Capital Flight," Policy Research Working Paper Series, No. 1186 (Washington, World Bank).

Dooley M. (1986). “An Analysis of External Debt Positions of Eight Developing Countries through 1990", Journal of Development Economics 21: 283-318.

Dornbusch, R. (1990), "Latin American Trade Misinvoicing as an Instrument of Capital Flight", Inter-American Development Bank, Occasional Paper No. 3, Washington, D.C.

Helpman, E. and A. Razin. 1978. A Theory of International Trade under Uncertainty. New York: Academic Press.

Jones, R. (1971) "A Three-Factor Model in Theory, Trade and History", in Trade, Balance of Payments and Growth: Essays in Honor of C.P, Kindleberger, J.N. Bhagwati (ed.) Amsterdam: North Holland. 
Jones, R. and F. Dei (1983). "International Trade and Foreign Investment: A Simple Model," Economic Inquiry 21(4): 449-464.

Jones, R., J. P. Neary and F. Ruane (1983). "Two-way Capital Flows: Cross Hauling in a Model of Foreign Investment", Journal of International Economics 14: 357-366.

Kilhstrom, R. E. and L. J. Mirman (1981). "Constant, Increasing and Decreasing Risk Aversion with Many Commodities", Review of Economic Studies 48(2): 271 - 280.

Markusen, J. (1995). "The Boundaries of Multinational Enterprises and the Theory of International Trade", Journal of Economic Perspectives 9(2): 169 - 189.

Markusen, J. and A. Venables (1999). "Foreign Direct Investment as a Catalyst for Industrial Development", European Economic Review 43: 335 - 356.

Mayer, W. (1976). "The Rybczynski, Stolper-Samuelson, and Factor Price Equalization Theorems under Price Uncertainty", American Economic Review 66: 796-808.

Newbery, D. M. G. and J. E. Stiglitz (1981). The Theory of Commodity Price Stabilization: A Study in the Economics of Risk. Oxford : Clarendon Press.

Pastor, M. (1989). Capital Flight and the Latin American Debt Crisis, Economic Policy Institute, Washington, D.C..

Pomery, J. (1983). "Restricted Stock Markets in Simple General Equilibrium Models with Production Uncertainty", Journal of International Economics 15, 253-276.

Pratt, J. W. (1964). "Risk Aversion in the Small and in the Large", Econometrica 32, 122-136.

Sakai, Y. (1978). "A Simple General Equilibrium Model of Production: Comparative Statics with Price Uncertainty", Journal of Economic Theory 19, 287-306.

Stiglitz, J. E. (1969). "Behavior Towards Risk with Many Commodities", Econometrica 37, 660-667.

World Bank (2001). World Development Indicators, 2001, CD-ROM Edition. Washington DC: World Bank. 
Zdanowicz, J., S. Pak and M. Sullivan (1999), "Brazil-United States Trade: Capital Flight Through Abnormal Pricing", The International Trade Journal, Vol. XIII, No. $4,423-443$ 
Figure 1. Per Capita Capital Flight and Inward Foreign Direct Investment (current US dollars per capita)

(East Asia and Pacific: EAP, Latin America and the Caribbean (LAC))
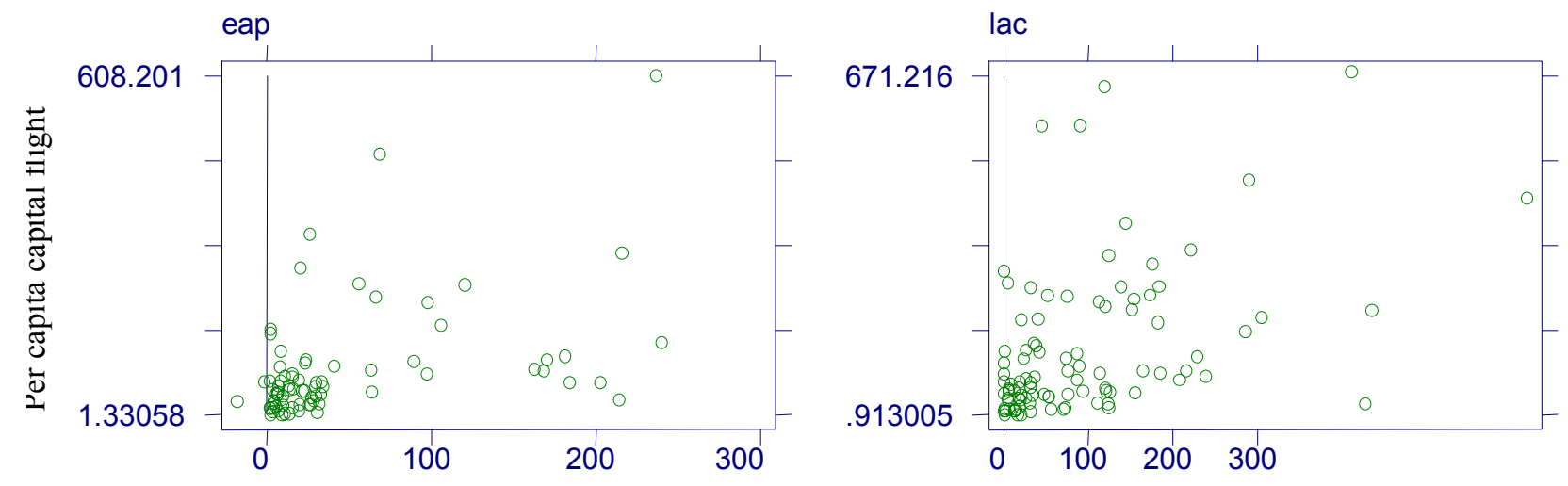

Per capita Foreign Direct Investment 
Figure 2. Annual Regional Averages of Per Capita Capital Flight and Inward Foreign Direct Investment,

(current US dollars per capita)

(East Asia and Pacific: EAP, Latin America and the Caribbean $(L A C)$ )

\section{_ Per Cap Capital Flight}

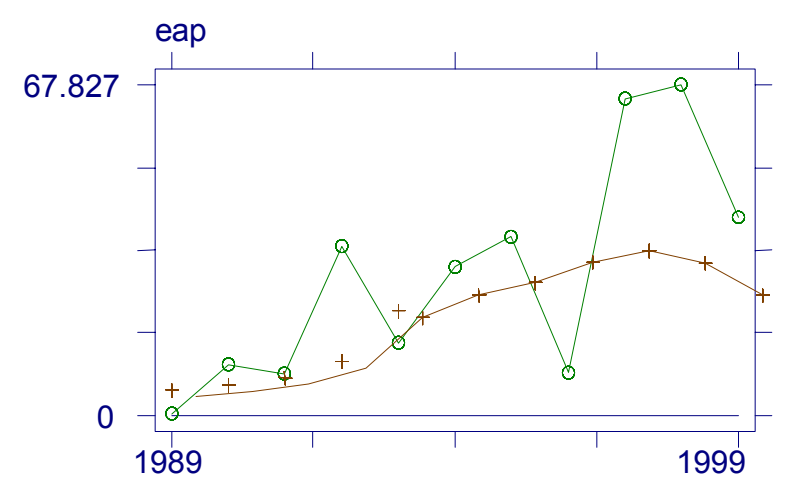

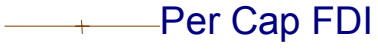

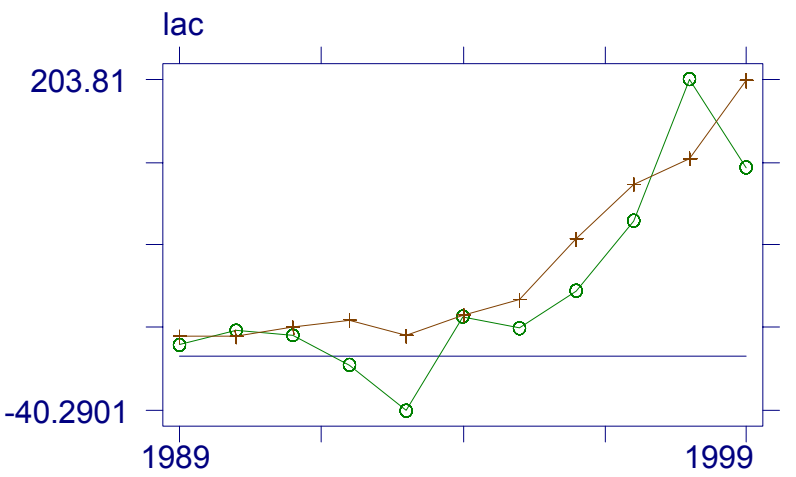

